\title{
Ethnomedicine, phytochemistry and pharmacology of Calotropis procera and Tribulus terrestris
}

\author{
Amina Mukhtar Dirir ${ }^{1}$, Abdul Jaleel Cheruth ${ }^{2}$, Taoufik Saleh Ksiksi ${ }^{3}$ \\ 1 Biology Department, UAE University, Abu Dhabi, UAE \\ 2Department of Arid Land Agriculture, College of Food and Agriculture, UAE University, Abu Dhabi, UAE \\ 33iology Department, College of Science, UAE University, Abu Dhabi, UAE; tksiksi@uaeu.ac.ae
}

\section{Abstract}

Medicinal plants possess an important advantage in the treatment of many diseases all over the world, especially in the developing countries. Simply because the toxicity associated with synthetic drugs has forced the scientific communities as well as the drug companies to seek other alternatives, such as the use of medicinal plants. Calotropis procera and Tribulus terrestris are examples of medicinal plants that possess different biological activities. Additionally, these two species are wide spread in the UAE harsh desert environment. Anti- microbial, anti-oxidant and anti-tumor activities exhibited by these two plants have been reported in many scientific investigations. Here, we attempt to review the current body of scientific knowledge associated with of the ethnomedicine, phytochemistry and pharmacology of Calotropis procera and Tribulus terrestris.

Keywords: Ethnomedicine, pharmacology, phytochemistry, Calotropis procera, Tribulus terrestris

\section{Introduction}

Plant-based natural products, animal derived natural products and minerals have been the foundation of treatment of different human diseases ${ }^{25}$. Many people around the world, especially in the developing countries, are increasingly relying on plant-derived traditional medicines. The world health organization defined medicinal plants as any plant that possess bioactive compounds in one or more of its organs that can be used for healing purposes ${ }^{13}$. Calotropis procera (Figure 1.) a plant of family Asclepiadaecae is an Ayurvedic plant that possess significant medicinal characteristics. It exists in many parts around the world with a worm climate in dry, sandy and alkaline soils ${ }^{4}$. Arid and semi-arid areas, are the main areas where Calotropis procera grow substantially without the need of pesticides, chemical fertilizers and irrigation ${ }^{47}$. Different Calotropis procera parts were employed for therapeutic purposes in the traditional medicines and their medicinal characteristics were emphasized by many scientists ${ }^{49}$. Calotropis procera latex, for example, is characterized by its significant medicinal value and pharmacological activities due to its high content of different phytochemicals like cardiac glycosides, alkaloids and steroids ${ }^{34}$.

Tribulus genus belongs to family zygophyllaceae that roughly contains 25 different plant species which grow as hairy herbs in tropical and warm areas ${ }^{43}$. Tribulus terrestris (Figure 2) is a well-recognized and vastly distributed plant of the genus Tribulus. Tribulus terrestris is known by various widespread names: puncture vine,

\footnotetext{
${ }^{*}$ Author for correspondence
}

Email: tksiksi@uaeu.ac.ae 
goat head, devil's thorn and Gokhru. It is an annual medicinal plant exists in the Mediterranean, subtropical and desert areas ${ }^{55}$. In traditional medicine, Tribulus terrestris have been used to treat different diseases due to its contents of different bioactive components like saponins, alkaloids, tannins, vitamin, glutamic acid and aspartic acid ${ }^{14}$. Many researchers investigated the biological activity of Tribulus terrestris. Plant extracts from the whole plant or fruits are currently used in various applications ranging from skin care to human hormones regulation. Other biological activities of Tribulus terrestris extract include anti-bacterial, antivirus, anti-inflammation activities ${ }^{16}$. The purpose of this work is to review the biological activities and phytochemistry of two important medicinal plants: Calotropis procera and Tribulus terrestris.

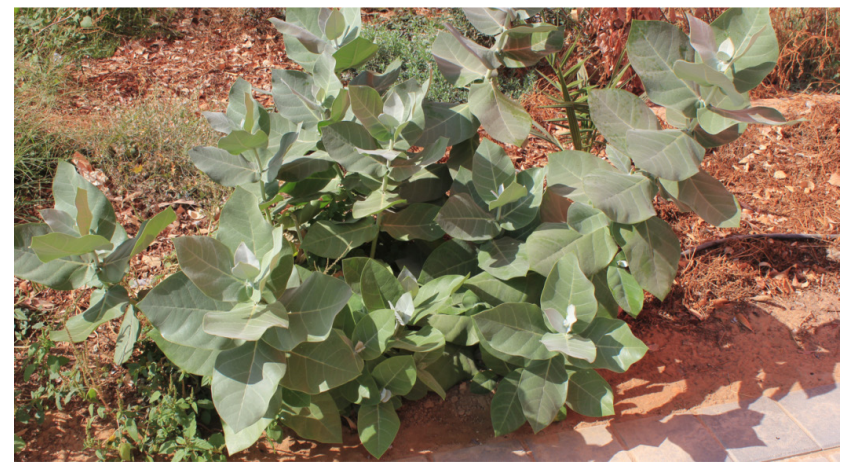

Fig. 1. An image of Calotropis procera grown in the UAE University Campus.

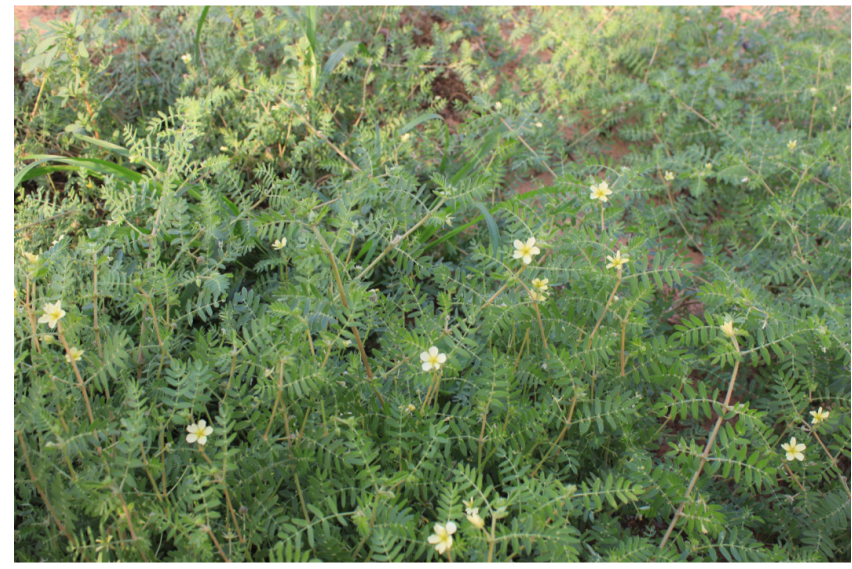

Fig. 2. An image of Tribulus terrestris grown in the UAE University Campus.

\section{Phytochemicals and Bioactive Compounds}

Phytochemicals are natural compounds produced by the plants and exhibit bothpharmacologicaland toxicological effects in humans and animals ${ }^{6}$. Plant natural compounds can be found and extracted from the different plant parts such as bark, leaves, flowers, roots, fruits and seeds ${ }^{52}$. Plants bioactive compounds have many benefits to the human's heath. They act as a substrates for biochemical reactions, as cofactors for enzyme-catalyzed reactions, inhibitors for enzymatic reactions and scavengers for reactive toxic compounds. Terpenoids, phenolics and alkaloids are some examples of phytochemicals that provides health benefits to the humans and prevent the occurrence of fatal diseases ${ }^{11}$.

\subsection{Calotropis procera}

Various studies investigated the phytochemicals constituents and the principal active compounds presented in Calotropis procera. One paper reported the phytochemicals presented in the aqueous, methnolic and ethanolic extract of Calotropis procera leaf and roots $^{29}$. Their results showed the presence of several phytochemicals such as alkaloids, flavonoids, tannins, saponins, cardiac glycosides, balsams, volatile oil and steroids. The aqueous extract contained the highest concentrations of this phytochemicals followed in order by the methanolic and ethanolic extract ${ }^{29}$. Other active chemical constituents isolated from the leaf and latex of Calotropis procera are calotropon, uscharine, calotoxin and calctin ${ }^{47}$. Another work confirmed the presence of coroglaucigenin, frugoside, corotoxigenin and calotropin in Calotropis procera seeds ${ }^{47}$.

\subsection{Tribulus terrestris}

Many studies discussed the phytochemicals constituents and the principal active compounds presented in Tribulus terrestris. A study by Hammoda and colleagues ${ }^{21}$ conducted a phytochemical screening of the aqueous and methanolic extract of Tribulus terrestris fruits and leaves. Results revealed the presence of alkaloids, 
flavonoids, saponins, tannins, and carbohydrates ${ }^{46}$. Different secondary metabolites have been isolated from the different parts of Tribulus terrestris. One study isolated eight bioactive compounds from the aerial part of Tribulus terrestris L., three of which were obtained for the first time from a natural source. The isolated novel bioactive compounds were two oligosaccharides and a stereoisomer of di-p-coumaroylquinic acid ${ }^{21}$. Other work published in phytochemistry journal, discussed the isolation of seven novel steroidal saponins from Tribulus terrestris fruits. The structure of saponins was determined using $1 \mathrm{D}$ and 2D NMR spectroscopy, mass spectroscopy and chemical methods. The isolated compounds were listed by ${ }^{53}$.

\section{Elemental Analysis}

More than 40 elements have been classified as essential elements to the life system and that support the survival of the living organisms ${ }^{56}$. The human body requires various nutrients and minerals in order to maintain a good health. Macro and micro-nutrients affect and support the different biochemical processes in the human body such as metabolism. Some mineral elements are chelated and associated with organic ligands to facilitate their bioavailability in the body system ${ }^{54}$. The elemental analysis of the medicinal plants is currently an object of study by the scientists. One of the driving causes to study and analyze the elemental analysis of medicinal plants is the need to observe the levels of elements, which possess potentially harmful effects on the human health such as $\mathrm{Hg}, \mathrm{Cd}$ and $\mathrm{Pd}^{35}$.

\subsection{Calotropis procera}

A study carried out at the College of Science, University of Sharjah, examined the elemental composition of Calotropis procera utilizing X-ray analytical microscopy ${ }^{4}$. The different plant parts (stalks, leaves and flowers) have been investigated qualitatively and quantitatively for their elemental content. Results revealed the presence of the major elements $\mathrm{Cl}, \mathrm{K}$ and $\mathrm{Ca}$ with different concentration. Other elements were found in the plant with low insignificant concentration $(\mathrm{Mg}, \mathrm{Si}, \mathrm{P}, \mathrm{Fe}, \mathrm{Sr}$, $\mathrm{Mn}, \mathrm{Br})^{4}$.

\subsection{Tribulus terrestris}

A work conducted at the Department of Biological Science, University of Sargodha, investigated the elemental composition of Tribulus terrestris using Atomic Absorption Spectrophotometer (AAS) ${ }^{17}$. Results confirmed the presence of different trace elements such as $\mathrm{Zn}, \mathrm{Cu}, \mathrm{Cr}, \mathrm{Ni}, \mathrm{Co}, \mathrm{Cd}, \mathrm{Pd}, \mathrm{Mn}$ and $\mathrm{Fe}$ and major elements such as $\mathrm{K}, \mathrm{Na}, \mathrm{Ca}$ and $\mathrm{Mg}$. Among the major elements, $\mathrm{Ca}$ was the highest in concentration presented in Tribulus terrestris and Fe was the highest in concentration among the trace element ${ }^{17}$.

\section{Ethno-Medicinal Properties}

In the tribal society, plants were widely employed as medicine and their healing properties were well known since early days. They use various plant species and different plant parts (stems, barks, leaves and roots) in the curing of different illness and diseases ${ }^{18}$. Ethnomedicine refers to the sum total of all information and practical enforcement, employed in diagnosis, prevention and removal of physical and mental imbalance, and depending solely on expertise and practice handed down from generation to generation, whether orally or in writing ${ }^{39}$. This huge documented knowledge about the medicinal properties of the plants has provided significant modern drugs ${ }^{28}$. Digitoxin, reserpine, tubocurarine, ephedrine, atropine and aspirin are examples of some modern drugs that were developed from the traditional folk medicines ${ }^{3}$.

\subsection{Calotropis procera}

Calotropis procera is plant species which has been employed in many folk medicines to cure a variety of diseases. The plant extracts of the different plant parts possess a significant medicinal value. Calotropis procera leaves were used to eliminate joint pain and minimize swelling ${ }^{48}$. Calotropis procera traditionally employed to treat different diseases like diarrhea, stomatic, sinus fistula and skin diseases. In addition, Calotropis procera leaves are employed to handle jaundice ${ }^{37}$. Calotropis procera bark powder is employed to remedy leprosy and elephantiasis. The root bark tissues are utilized 
to treat a different of diseases such as fever, malaria, leprosy, and snake bite ${ }^{47}$. The stem part was also used by the native people to cure enlargements of abdominal viscera, intestinal worms and leucoderma ${ }^{1}$. Moreover, in traditional folk medicine, the plant has been employed as an antifungal and antipyretic agent ${ }^{48}$. Several traditional medicinal systems like the Sudanese, Unani and Indian systems have extensively employed Calotropis procera to cure different illness such as ulcers, piles, spleen, liver and abdomen diseases ${ }^{31}$.

\subsection{Tribulus terrestris}

Tribulus terrestris is one of the Far East medicinal plants that have been widely employed in the folk medicine. Tribulus terrestris has been utilized traditionally, to treat kidney dysfunctions, colic pains, hypertension and hyper-cholesterolemia ${ }^{38}$. Tribulus terrestris fruits have been employed in the Chinese ethno medicine to cure eye problems, edema, veiling, morbid leucorrhea and abdominal distention ${ }^{2}$. In China and India, Tribulus terrestris is utilized to handle kidney, liver, urinary and cardiovascular. In addition, Tribulus terrestris was extensively used in Greek history to cure headache, nervous disruption, constipation and sexual dysfunction $^{38}$. Tribulus terrestris roots and fruits are beneficial in rheumatism, piles, renal, vesical calculi, impotency and general weakness ${ }^{2}$. It has also been reported that Tribulus terrestris used in the traditional medicine as astonic. Tribulus terrestris is well known in traditional medicine to promote flow of urine, mitigates the urinary tract membrane and inhibits the generation of oxalate which is a substance that gives rise to microcrystals ${ }^{44}$. In addition, it has been reported that saponins from $T$. terrestris maintained the heart efficiency by dilating coronary arteries ${ }^{44}$.

\section{Anti-Tumor Activity}

To date, scientific investigations concentrate on the biological action associated with the non-nutritional compounds that prohibit the occurrence of some deadly diseases like cancer called phytochemicals ${ }^{42}$. In particular, polyphenols are among the varied phytochemicals with their capability of cancer prevention ${ }^{13}$. Plants are well known for their phytochemical content, and cancer prevention through the plant bioactive natural compounds is gaining a lot of interest ${ }^{7}$.

\section{1 Calotropis procera}

Different research have been performed to study the anti-cancer activities and the cytotoxicity associated with Calotropis procera extract. One work studied the anti-cancer potential of Calotropis procera root extract against Hep2 cancer cells ${ }^{30}$. Different extracts were prepared: methanolic extract, hexane extract, aqueous extract and ethyl acetate extract. Tetrazolium bromide (MTT) colorimetry was used to study the cellular proliferation activities. Results confirmed the cytotoxity and anticancer activities of Calotropis procera methanolic, hexane and ethyl acetate extract. However, the aqueous extract did not exhibit any cytotoxic effects. Ethyl acetate extract exhibited the best cytotoxic effect (96.3\%) against Hep2 cancer cells followed in order by methanolic extract (72.7\%) and hexane extract (60.5\%). In addition, Calotropis procera root extract altered the morphology of the Hep2 cancer cells and led to apoptosis initiation of Hep2 cancer cells ${ }^{30}$.

\subsection{Tribulus terrestris}

One study examined the anti-tumor activities of Tribulus terrestris fruit extract against breast cancer cells ${ }^{32}$. The cytotoxicity results, revealed that the average Inhibitory Concentration (IC50) was $380 \mathrm{~g} / \mathrm{ml}$ for Daltons Lymphoma Ascites (DLA) and $420 \mathrm{~g} / \mathrm{ml}$ for Ehrlichs Ascites Carcinoma (EAC) cells. The results suggested the anti-cancer potential of Tribulus terrestris fruit extract ${ }^{32}$.

\section{Antimicrobial Activity}

Infectious diseases constitute a high percentage of the health problems, particularly in the developing countries ${ }^{47}$. Recently, several microorganisms and pathogens have developed resistance to various antibiotics, which has created a massive problem in the treatment of the microbial diseases ${ }^{47}$. Generally, bacteria for example, are genetically characterized by their capability to transmit and develop such durability to drugs, which are employed for therapeutic purposes ${ }^{19}$. This situation along with the toxicity associated with many antifungal and antiviral drugs has forced the scientists and the pharmaceutical companies to look for alternative and novel drug sources, such as medicinal plants ${ }^{13}$. Antimicrobial agents are highly present in the medicinal plants ${ }^{12}$. Plants utilize such phytoconstituents 
to defend themselves form the different pathogenic insects, bacteria, fungi and protozoa ${ }^{12}$. Plant-based antimicrobial compounds are useful in the treatment of the infectious diseases. Majority of those compounds alleviate the side effects associated with the synthetic drugs $^{47}$. However, among the different 250,000-500,000 plant species, a small portion has been investigated for their biological and antimicrobial activities ${ }^{27}$.

\subsection{Calotropis procera}

A study was performed utilizing ethanol, aqueous and chloroform extracts of the leaf and the latex of Calotropis procera ${ }^{23}$. The different extracts were tested against six bacteria: Escherichia coli, Staphylococcus aureu, Staphylococcus albus, Streptococcus pyogenes, Streptococcus pneumonia and Pseudomonas aeruginosa, three fungi: Aspergillus niger, Aspergillus flavus, Microsporium boulardii and one yeast Candida albicans. Agar well diffusion method and paper disk method have been utilized to investigate the antimicrobial activities of Calotropis procera extract. The results revealed that the ethanolic extract of the latex and the leaf exhibited the best antimicrobial activity against the tested microorganisms then the chloroform and the aqueous extract. The ethanolic extract of the latex of Calotropis procera exhibited the widest inhibition zone $(14.1 \mathrm{~mm})$ against E. coli employing well-diffusion method. However, it exhibited a $9.9 \mathrm{~mm}$ zone of inhibition using the disc plate method for the same bacteria. The three different extracts prohibited the growth of all the six bacterial isolates expect the aqueous extract of both the latex and the leaf of Calotropis procera failed to prevent the growth of the Pseudomonas aeruginosa and Streptococcus pyogenes bacterial strains. Similarly, the aqueous extract was inefficient in the inhibition of the tested fungi, while the ethanolic and the chloroform extract were effective in inhibiting the growth of the fungi ${ }^{23}$. In another study, the antimicrobial activity of the methanol and chloroform extracts of Calotropis procera seeds was analyzed ${ }^{22}$. Seven microorganisms were used namely: Staphylococcus aureus, Bacillus subtilis, Escherichia coli, Mycobacterium smegmatis, Aeromonas hydrophila, Morganella morganii and Proteus vulgaris. Results revealed that the chloroform extract showed a better antimicrobial activity and more efficiency than the methanol extract ${ }^{22}$. A study evaluated the antifungal activities of the Calotropis procera bark.
The extract was prepared and tested against four fungal strains namely: Candida albicans, Tinea capitis, Epidermophyton floccosum and Microsporum canis. The experimental work found that both the ethanolic and water extract was efficient in inhibiting the growth of the fungal strains especially the Candida albicans and Tinea capitis strains. However, it showed a moderate activity against Epidermophyton floccosum and Microsporum canis fungal strains $s^{5}$. A recent work, studied the in vitro effect of the Ethyl Acetate Extract Of Calotropis procera Latex (EAECPL) against one of the common parasites namely Haemonchus contortus ${ }^{9}$. In the Egg Hatching Test (EHT), results showed that the ethyl acetate extract of the plant latex inhibited the larval hatching by $91.8 \%$ at a concentration of $4 \mathrm{mg} / \mathrm{ml}$. The latex extract inhibited the larvae growth and development by $99.8 \%$ at $1 \mathrm{mg} /$ $\mathrm{ml}$ concentration. The extract concentrations also exhibited a dose-dependent manner, with an efficient concentration (EC50) of $1.6 \mathrm{mg} / \mathrm{ml}$ and $0.22 \mathrm{mg} / \mathrm{ml}$ for EHT and LDT respectively ${ }^{9}$. In the adult Worms Motility Test (WMT), the plant latex extract inhibited the motility of the worms by $100 \%$ at $100 \mathrm{mg} / \mathrm{ml}$ concentration ${ }^{9}$.

Different studies examined the antifungal activity of the proteins presented in the latex of Calotropis procera. One study reported the functional properties and biochemical characterization of chitinases-ahydrolytic enzyme characterized by their ability to degrade the chitin which is a polysaccharide found in the fungal cell walls-purified from Calotropis procera latex. Experiments were performed on two phytopathogenic fungi namely Fusarium oxysporum and Colletotrichum gloeosporioides to test the antifungal activity of the latex chitinases. Results showed that chitinases were somewhat active on C. gloeosporioides, while it did not inhibit the spore germination and hyphae growth of $F$. oxysporum. Chitinases failure to show antifungal activity against $F$. oxysporum may be attributed to a complex relationship between proteins specificity against fungal species ${ }^{15}$. In another work, osmotin purified from Calotropis procera latex, was tested for its antifungal activity ${ }^{10}$. Osmotin was tested against three phytopathogenic fungal strains namely: Fusarium solani, Neurospora sp. and Colletotrichum gloeosporioides. Osmotin exhibited antifungal activity on all three species with an Fusarium solani, Neurospora sp. and Colletotrichum gloeosporioides with an inhibitory concentration (IC50) $=67.0 \mathrm{~g} /$ 
$\mathrm{ml}, 57.0 \mathrm{~g} / \mathrm{ml}$ and $32.1 \mathrm{~g} / \mathrm{ml}$, respectively. The protein, however, lost its antifungal activity when it is treated with Dithiothreitol (DTT), reducing agent, which indicate that the presence of disulfide bond stabilizing the proteins and it's important in its biological function ${ }^{10}$. The mechanism of action of this protein was examined in a different work, utilizing Fusarium solani fungal strain. Results indicated that osmotin purified from Calotropis procera latex stimulated the membrane permeabilization of hyphae and spores permitting propidium iodine uptake ${ }^{51}$.

\subsection{Tribulus terrestris}

The antibacterial activity of Tribulus terrestris grown in Iran was assessed ${ }^{24}$. Different plant parts have been used (fruits, stems + leaves and roots) to assess the in vitro antibacterial activity of the methanolic extract. Four different bacteria namely: Staphylococcus aureus, Enterococcus faecalis, Escherichia coli and Pseudomonas aeruginisa were used in this investigation. The average minimum inhibitory concentration of the (fruits, stems + leaves) extract was $2 \mathrm{mg} / \mathrm{ml}$ for all the four bacterial strains. In addition, the minimum inhibitory concentration of the root extract was $4 \mathrm{mg} / \mathrm{ml}$ against Staphylococcus aureus, Enterococcus faecalis and Escherichia coli and $2 \mathrm{mg} / \mathrm{ml}$ against Pseudomonas aeruginisa. In agar diffusion method, the plant extract of all the different parts exhibited a great activity against all the bacterial strains ${ }^{24}$. Another study ${ }^{57}$ evaluate the antifungal activity of eight isolated steroidal saponins from T. terrestris which is shortened as the following: TTS-8, TTS-9, TTS-10, TTS-11, TTS-12, TTS-13, TTS-14, and TTS-15. The eight isolated saponins were identified as listed in the Table 1.

The in vitro inhibitory effects of the isolated saponins were tested against six fluconazole resistant yeasts namely: Candida albicans, Candida glabrata, Candida parapsilosis, Candida tropicalis, Candida krusei, and Cryptococcus neoformans employing micro broth dilution assay. Results indicated that TTS-12 and TTS15 were extremely potent against most of the pathogenic fungal strains ${ }^{57}$.

Table 1: The eight isolated steroid saponins from Tribulus terrestris as reported by ${ }^{57}$

\begin{tabular}{|c|c|}
\hline Item & Compound Name \\
\hline 1 & hecogenin-3-O-b -Dglucopyranosyl(14)-b -D-galactopyranoside (1, TTS-8) \\
\hline 2 & tigogenin-3-O-b -D-glucopyranosyl(14)-b -D-galactopyranoside(2, TTS-9) \\
\hline 3 & hecogenin-3-O-b -D-glucopyranosyl(12)-b -D-glucopyranosyl(14)-b-D-galactopyranoside (3,TTS-10) \\
\hline 4 & hecogenin-3-O-b -D-xylopyranosyl(13)-b -D-glucopyranosyl(14)-b - D-galactopyranoside (4, TTS-11) \\
\hline 5 & $\begin{array}{l}\text { tigogenin-3-O-b -D-xylopyranosyl(12)-[b -D-xylopyranosyl- (13)]-b -D-glucopyranosyl(14)-[a } \\
\text {-L-rhamnopyranosyl(12)]-b-D-galactopyranoside (5, TTS-12) }\end{array}$ \\
\hline 6 & $\begin{array}{l}\text { 3-O-b -D-xylopyranosyl(12)-[b -D-xylopyranosyl(13)]-b - D-glucopyranosyl(14)-[a -L-rhamnopyranosyl(12)]-b } \\
\text {-D- galactopyranosyl-26-O-b -D-glucopyranosyl-22-methoxy-(3b, 5a,25R)-furostan-3,26-diol }(6, \text { TTS-13) }\end{array}$ \\
\hline 7 & $\begin{array}{l}\text { hecogenin-3-Ob-D-glucopyranosyl(12)-[b -D-xylopyranosyl(13)]-b - D-glucopyranosyl(14)-b } \\
\text {-D-galactopyranoside (7, TTS-14) }\end{array}$ \\
\hline 8 & $\begin{array}{l}\text { tigogenin-3-O-b -D-glucopyranosyl(12)-[b -D-xylopyranosyl(13)]-b - D-glucopyranosyl(14)-b } \\
\text {-D-galactopyranoside(8, TTS-15) }\end{array}$ \\
\hline
\end{tabular}

\section{Antioxidant Activity}

Antioxidants protect the human cells from the harm caused by the free radicals such as super oxide anion and hydroxyl radicals. Free radicals, if not eliminated, may cause macromolecules damage like proteins, lipids, DNA and carbohydrates which eventually will result in abnormalities leading to serious diseases. The antioxidants produced by the human body are not enough to prevent the occurrence of oxidative stress.
Therefore, humans compensate this deficiency by consuming a plant's natural products. Plants contain a various types of free radical scavenging phytochemicals like phenols, flavonoids and vitamins ${ }^{13}$.

\subsection{Calotropis procera}

The antioxidant properties of Calotropis procera extracts were assessed by their capability to scavenge the free radical (DPPH). The inhibitory concentration (IC50) of 
the methanolic extract was $110.25 \mathrm{~g} / \mathrm{ml}$, which suggest a potent antioxidant activity of Calotropis procera plant species. However, the inhibitory concentration of the water extract of leaves exhibited a moderate antioxidant activity $^{36}$. Another work examined the antioxidant activity of Calotropis procera flower extract. The free radical scavenging activity was evaluated against 1 , 1-Diphenyl-2-Picryl Hydrazyl (DPPH), hydroxyl radical, hydrogen peroxide radical, reducing power and ferric thiocyanate method. Results revealed that the methanolic extract of Calotropis procera flowers possess a significant free radical scavenging activity ${ }^{41}$. A work published in the Journal of Applied Bioscience, examined the antioxidant activity of the latex, leaf and roots of Calotropis procera ${ }^{8}$. The antioxidant activity was assessed using (DPPH) assay. According to the results, the lyophilized latex showed the highest antioxidant activity with an inhibitory concentration (IC50 $=0.060$ $\mathrm{mg} / \mathrm{ml}$ ). On the other hand, the root extract showed the lowest Inhibitory Concentration (IC50 $=0.27 \mathrm{mg}$ / $\mathrm{ml})^{8}$. A recent study reported the antioxidant and antiapoptotic properties of Calotropis procera latex on Clarias gariepinus that is treated with the chemical pollutant 4-nonylphenol ${ }^{45}$. When the organism is treated with toxic chemical, superoxidase dismutase, catalase, acetlycholinstrase (AchE), glutathione s-transferase and cortisol, G6PDH) exhibited a significant increase in their activity $(\mathrm{P}<0.05)$. However, when the tested organism was treated with the chemical pollutant (4-nonylphenol) plus the latex of Calotropis procera, the activity of those enzymes decreased, which indicate an antioxidant potential $^{45}$.

\subsection{Tribulus terrestris}

Different assays have been performed to assess the antioxidant activity of Tribulus terrestris extract. The (DPPH) assay, (ABTS) assay, (FRAP) assay and (FTC) assay were the main methods that have been used in this investigation ${ }^{58}$. Results suggested a significant antioxidant activity exhibited by the extracts with an Inhibitory Concentration (IC50) between 2.84 and $4.56 \mathrm{mg} / \mathrm{ml}$ and from $0.28 \mathrm{mg} / \mathrm{mL}$ to $0.31 \mathrm{mg} / \mathrm{mL}$ for DPPH and ABTS activity, respectively. In addition, the extract exhibited a better FRAP activity compared to the positive control (BHT) and showed an ability to control lipid peroxidation in linoleic acid system ${ }^{58}$.

\section{Allelopathic Effect}

Allelopathy is the effect of one plant on another plant growing in its vicinity by emitting metabolic toxic chemicals in the environment ${ }^{33}$. Allelopathy can be either beneficial or harmful to the organisms in the surrounding environment ${ }^{26}$. These released chemicals can affect the germination, growth or development of the adjacent plants. Allelopathy can be considered as a biological control component in which plants are used to diminish the growth of other plants in the surrounding environment. Allelochemicals and allelopathy are an object of study by many scientists particularly their pesticidal potential $^{33}$.

\subsection{Calotropis procera}

A recent study examined the influence of Calotropis procera hydro extract on the development of Brassica oleracea. Brassica seeds were treated with different concentration of Calotropis procera leafs, fruits and flowers extracts. A high concentration of the aqueous extract noticeably diminished seed germination, plumule length and radical length as compared with distilled water (control). Such results highlight the phytotoxicity and allelopathic potential of Calotropis procer ${ }^{20}$.

\section{Conclusion}

In short, the aim of this attempt was to present an overview of the phytochemistry, ethnobiology and biological properties of two important medicinal plant species: Calotropis procera and Tribulus terrestris. Both species are widespread in the UAE harsh desert environment. Numerous scientific investigations assessed the biological properties of Calotropis procera as well as Tribulus terrestris and studied the chemical constituents. Calotropis procera and Tribulus terrestris extracts were widely studied and their anti-microbial, anti-oxidant and anti-tumor activities were largely examined.

The consistent and substantial biological activities exhibited by these two plants should encourage the scientific community and pharmaceutical industries to take closer look into these two species. This will very likely lead to potentially develop plant-derived novel drugs, which are safer and with less side effects. A lesser 
reliance on synthetic drugs, and their increasing side effects, will potentially be the expected outcome.

\section{References}

1. Abhishek D, Mohit C, Ashish G, Ameeta A. Medicinal utility of calotropis pro- cera (ait.) $\mathrm{r}$ br as used by natives of village sanwer of indore district, Madhya Pradesh. International Journal of Pharmacy and Life Sciences 2010; 1:188-90.

2. Akram M, Asif H, Akhtar N, Shah PA, Uzair M, Shaheen G, Shamim T, Shah SA, et al. Tribulus terrestris linn.: A review article. Journal of Medicinal Plants Research. 2011; $5(16)$.

3. Alsarhan A, Sultana N, Al-Khatib A, Kadir MRA. Review on some Malaysian traditional medicinal plants with therapeutic properties. Journal of Basic and Applied Sciences. 2014; 10:149. https://doi.org/10.6000/19275129.2014.10.20

4. Attaelmanan AG, Kawam MA. Determining the elemental composition of Calotropis procera using X-ray Analytical Microscopy. X-Ray Spectrometry 2012; 41(5):284-7. DOI: 10.1002/xrs.2393. https://doi.org/10.1002/xrs.2393

5. Bajpayee KK. Antifungal activities of bark extract of Calotropis procera (Ait.) $\mathrm{R} \mathrm{Br}$ Kaptain. International Journal of Advances in Scientific Research 2015; 1(08):322-8. DOI: 10.7439/ijasr. https://doi.org/10.7439/ ijasr

6. Bernhoft A. Bioactive compounds in plants: Benefits and risks for man and animals. Proceedings from a Symposium Held in Norwegian Academy of Science and Letters; Oslo. 2008 Nov 13-14.

7. Biswas J, Roy M, Mukherjee A. Anticancer drug development based on phytochemicals. Journal of Drug Discovery, Development and Delivery. 2015; 2(1):1-6.

8. Joshi R. Analysis of antioxidant activity in extracts of Calotropis procera (Ait.) R Br. Journal of Applied Biosciences. 2009; 17:899-903.

9. Cavalcante GS, de Morais SM, Andre WP, Ribeiro WL, Rodrigues AL, De Lira FC, Viana JM, Bevilaqua $\mathrm{CM}$. Chemical composition and in vitro activity of Calotropis procera (Ait.) latex on Haemonchus contortus. Veterinary Parasitology 2016; 226:22-5. DOI: 10.1016/j. vetpar.2016.06.012. Available from: http://linkinghub. elsevier.com/retrieve/pii/S0304401716302205. https:// doi.org/10.1016/j.vetpar.2016.06.012

10. De Freitas CDT, Lopes JLDS, Beltramini LM, De Oliveira RSB, Oliveira JTA, Ramos MV. Osmotin from
Calotropis procera latex: New insights into structure and antifungal properties. Biochimica et Biophysica Acta - Biomembranes. 2011; 1808(10):2501-7. DOI: 10.1016/j.bbamem.2011.07.014. Available from: http:// dx.doi.org/10.1016/ j.bbamem.2011.07.014. https://doi. org/10.1016/j.bbamem.2011.07.014

11. Dillard CJ, German JB, Phytochemicals, nutraceuticals and human health. J Sci Food Agric. 2000; 80(12):1744. https:// doi.org/10.1002/1097-0010(20000915)80:12<1744::AIDJSFA725>3.3.CO;2-N https://doi.org/10.1002/10970010(20000915)80:12<1744::AID-JSFA725>3.0.CO;2-W

12. District DK. Antimicrobial activity of medicinal plants against human pathogenic bacteria. International Journal of Recent Advnaces in Multi-disciplinary Research. 2013; 4(7):653-8.

13. Doughari JH. Phytochemicals: Extraction methods, basic structures and mode of action as potential chemotherapeutic agents. Agricultural and Biological Sciences. 2009; 1-33.

14. Fatima L, Sultana A, Ahmed S, Sultana S. Pharmacological activities of tribulus terrestris linn: A systemic review. Wor J Pharm Pharmac Sci 2015; 4(02):136-50.

15. Freitas CD, Viana CA, Vasconcelos IM, Moreno FB, Lima-Filho JV, Oliveira HD, Moreira RA, MonteiroMoreira ACO, Ramos MV. First insights into the diversity and functional properties of chitinases of the latex of Calotropis procera. Plant Physiology and Biochemistry. 2016; 108:361-71. DOI: 10. 1016/j.plaphy.2016.07.028. Available from: http://linkinghub.elsevier.com/retrieve/ pii/S0981942816302959

16. Di Sansebastiano GP. Quality and efficacy of Tribulus terrestris as an ingredient for dermatological formulations. Open Dermatology Journal. 2013; 7(1):1-7. $\quad$ DOI: $\quad 10.2174 / 1874372201307010001$. Available from: http://ovidsp.ovid.com/ovidweb. cgi? $\mathrm{T}=\mathrm{JS}\{\&\} \mathrm{PAGE}=$ reference $\{\&\} \mathrm{D}=\quad$ emed $11\{\&\}$ NEWS $=\mathrm{N}\{\&\} A N=2013581280 \quad$ https://doi. org/10.2174/1874372201307010001

17. Ghani A, Ali Z, Ishtiaq $M$, Maqbool $M$, Parveen S. Estimation of macro and micro nutrients in some important medicinal plants of Soon Valley, District Khushab, Pakistan. African Journal of Biotechnology. 2012; 11(78):14386-91. DOI: 10.5897/AJB12.762. https:// doi.org/10.5897/AJB12.762

18. Gibji N, Ringu N, Dai N. Ethnomedicinal knowledge among the adi tribes of lower dibang valley district of Arunachal Pradesh, India. International Research Journal of Pharmacy 2012; 3:223-9. 
19. Girish HV, Satish S. Antibacterial activity of important medicinal plants on human pathogenic bacteria- A comparative analysis. World Applied Sciences Journal. 2008; 5(3):267-71.

20. Gulzar A, Siddiqui MB. Allelopathic effect of Calotropis procera ( Ait) $\mathrm{R} \mathrm{Br}$ on growth and antioxidant activity of Brassica oleracea var botrytis. Journal of the Saudi Society of Agricultural Sciences. 2016. DOI: 10.1016/j. jssas.2015.12.003. Available from: http://dx.doi.org/ 10.1016/j.jssas.2015.12.003 https://doi.org/10.1016/j. jssas.2015.12.003

21. Hammoda HM, Ghazy NM, Harraz FM, Radwan MM, ElSohly MA, Abdallah II. Chemical constituents from Tribulus terrestris and screening of their antioxidant activity. Phytochemistry. 2013; 92:153-9. DOI: 10.1016/j. phytochem. 2013.04.005.

22. Jain SC, Sharma R, Jain R, Sharma RA. Antimicrobial activity of Calotropis procera. Fitoterapia. 1996; 67(3):275-7.

23. Kareem SO, Akpan I, Ojo OP. Antimicrobial activities of Calotropis procera on selected pathogenic microorganisms. African Journal Biomedical Research. 2008; 11(1):105-10. DOI: 10.4314/ajbr.v11i1.50674. https://doi.org/10.4314/ ajbr.v11i1.50674

24. Kianbakht S, Jahaniani F. Evaluation of antibacterial activity of tribulus terrestris L Growing in Iran. IJPT. 2003; 2(1):22-4.

25. Lahlou $M$. The success of natural products in drug discovery. Pharmacology and Pharmacy. 2013; 4(Jun):17-31. DOI: 10.4236/pp.2013.43A003.Available from: $\quad$ http://dx.doi.org/10.4236/pp.2013.43A003\$ delimiter"026E30F\$nhttp://www.scirp.org/journal/pp.

26. Li ZH, Wang Q, Ruan X, Pan CD, Jiang DA. Phenolics and plant allelopathy. Molecules. 2010; 15(12):8933-52. DOI: 10.3390/molecules15128933. https://doi.org/10.3390/ molecules 15128933

27. Mahesh B, Satish S. Antimicrobial activity of some important medicinal plant against plant and human pathogens. World Journal of Agricultural Sciences. 2008; 4:839-43. Available from: http://idosi.org/wjas/wjas4(s)/7. pdf.

28. Mahmoud T, Gairola S. Traditional knowledge and use of medicinal plants in the eastern desert of egypt: a case study from wadi el-gemal national park. Journal of Medicinal Plants 2013;1(6).

29. Mainasara MM, Aliero BL, Aliero AA, Yakubu M. Phytochemical and antibacterial properties of root and leaf extracts of calotropis procera. Nigerian Journal of Basic and Applied Science. 2012; 20(1):1-6.
30. Mathur R, Gupta SK, Mathur SR, Velpandian T. Anti-tumor studies with extracts of Calotropis procera (Ait) $\mathrm{R}$ Br root employing Hep2 cells and their possible mechanism of action. Indian Journal of Experimental Biology. 2009; 47(5):343-8. PMid:19579799

31. Meena AK, Yadav AK, Niranjan US, Singh B, Nagariya AK, Sharma K, Gaurav A, Sharma S, Rao M. A review on calotropis procera linn and its ethnobotany, phytochemical, pharmacological profile. Drug Invention Today. 2010; 185-90.

32. Menon D, Dharmapal S, Achuthan C, Babu T. Cytotoxic and antitumor effects of tribulus terrestris 1 fruit methanolic extract. Journal of Pharmacognosy and Phytochemistry. $2014 ; 3(2)$.

33. Mishra A. Allelopathic properties of Lantana camara. International Research Journal of Basic and Clinical Studies. 2015; 3(1):13-28.

34. Mohamed NH, Liu M, Abdel-Mageed WM, Alwahibi LH, Dai H, Ismail MA, Badr G, Quinn RJ, Liu X, Zhang L, Shoreit AAM. Cytotoxic cardenolides from the latex of Calotropis procera. Bioorganic and Medicinal Chemistry Letters 2015; 25(20):4615-20. DOi:10.1016/j.bmcl.2015.08.044. Available from: http://dx.doi.org/10.1016/j.bmcl. 2015.08.044. https://doi.org/10.1016/j.bmcl.2015.08.044

35. Morabad RB, Patil SJ, Tapash RR. First series transition elemental analysis in some therapeutically important medicinal plants by AAS method. Journal of Materials and Environmental Science. 2013; 4(2):171-6.

36. Yesmin MN, Uddin SMSN, Akond MA. Antioxidant and antibacterial activities of society. 2005; 28(Dec):2225-30.

37. Murti Y, Yogi B, PathakD. Pharmacognostic standardization of leaves of calotropis procera (ait) $\mathrm{r}$ br (asclepiadaceae). International Journal of Ayurveda Research. 2010; 1(1):14. https://doi.org/10.4103/0974-7788.59938 PMid:20532092 PMCid:PMC2876921

38. Nath KMN. Chemical composition and nutritive value of t terrestris linn. Indian Journal of Animal Science. 1970; 434-7.

39. Obute GC. Ethnomedicinal plant resources of southeastern nigeria. Ethnobotanical Leaflets. 2005; 2005(1):5.

40. Quazi S, Mathur K, Arora S, Wing P. Calotropis Procera: An Overview of Its Phytochemistry and Pharmacology. IJOD Indian Journal of Drugs. 2013; 1(12):63-9. Available from: www.drugresearch.in.

41. Prabha MR, Vasantha K. Antioxidant, cytotoxicity and polyphenolic con-tent of calotropis procera (ait) $\mathrm{r}$ br flowers. Journal of Applied Pharmaceu-tical Science 2011; 1(7):136-40. 
42. Russo M, Spagnuolo C, Tedesco I, Russo GL. Phytochemicals in cancer pre- vention and therapy: Truth or dare? Toxins. 2010; 2(4):517-51. DOI: 10.3390/toxins2040517. https:// doi.org/10.3390/toxins2040517

43. Samy MN, Bish MM, Ahmed AA, Sayed HM, Kamel MS. Pharmacognostical studies on flower of tribulus terrestris L. Journal of Pharmacognosy and Phytochemistry. 2013; 1(5):18.

44.SamyRP, PushparajPN, GopalakrishnakoneP.Acompilation of bioactive compounds from ayurveda. Bioinformation. 2008; 3(3):100. https://doi.org/10.6026/97320630003100 PMid:19238245 PMCid:PMC2639691

45. Sayed AEDH, Mohamed NH, Ismail MA, Abdel-Mageed WM, Shoreit AAM. Antioxidant and antiapoptotic activities of Calotropis procera latex on Catfish (Clarias gariepinus) exposed to toxic 4-nonylphenol. Ecotoxicology and En-vironmental Safety. 2016; 128:189-94. DOI: 10.1016/j.ecoenv.2016.02.023. https://doi.org/10.1016/j. ecoenv.2016.02.023

46. Sharma M, Kumar A, Sharma B, Dwivedi N. Evaluation of phytochemical compounds and antimicrobial activity of leaves and fruits Tribulus terrestris. European Journal of Experimental Biology. 2013; 3(5):432-6.

47. Sharma R, Thakur GS, Sanodiya BS, Savita A, Pandey M, Sharma A, Bisen PS. Therapeutic potential of Calotropis procera: A giant milkweed. Journal of Pharmacy and Biological Science. 2012; 4(2):42-57. DOI: 10.9790/30080424257. https://doi.org/10.9790/3008-0424257

48. Shrivastava A, Singh S, Singh S. Phytochemical investigation of different plant parts of calotropis procera. International Journal of Scientific and Research Publications. 2013; 3(3).

49. Silva MCC, da Silva AB, Teixeira FM, de Sousa PCP, Rondon RMM, Honrio JER, Sampaio LRL, Oliveira SL, Holonda ANM, de Vasconcelos SMM. Therapeutic and biological activities of Calotropis procera (Ait) R Br. Asian Pacific Journal of Tropical Medicine. 2010; 3(4):332-6. DOI: 10.1016/ S1995-7645(10)60081-8.

50. Ksiksi, Taoufik, Chedia Guenaoui, and Nael Fawzi. "Early growth stages of the rare Acridocarpus orientalis in the UAE-A First step towards conservation." Nat Resour 3.1 (2012).
51. de Freitas CDT, Nogueira FCS, Vasconcelos IM, Oliveira JTA, Domont GB, Ramos MV. Osmotin purified from the latex of Calotropis procera: Biochemical characterization, biological activity and role in plant defense. Plant Physiology and Biochemistry. 2011; 49(7):738-43. DOI: 10.1016/ j.plaphy.2011.01.027. Available from: http:// dx.doi.org/10.1016/j.plaphy.2011.01.027 https://doi. org/10.1016/j.plaphy.2011.01.027

52. Tiwari P, Kumar B, Mandeep K, Kaur G, Kaur H. Phytochemical screening and Extraction: A Review. Internationale Pharmaceutica Sciencia. 2011; 1(1):98-106.

53. Xu Y, Liu Y, Xu T, Xie S, Si Y, Liu Y, Zhou H, Liu T, Xu D. A new furostanol glycoside from tribulus terrestris. Molecules. 2010; 15(2):613-8. DOI: 10.3390/molecules 15020613. https://doi.org/10.3390/molecules15020613

54. Yagi S, Rahman AEA, Elhassan GOM, Mohammed AMA. Elemental analysis of ten sudanese medicinal plants using $\mathrm{X}$-ray fluorescence. Journal of Applied and Industrial Sciences. 2013; 1(1):49-53.

55. Yanala SR. A recent phytochemical review fruits of Tribulus terrestris Linn. J Pharm Sci and Res. 2016; 8(3):132-40.

56. Zafar M, Khan MA, Ahmad M, Jan G, Sultana S, Marwat SK, Ahmad F, Jabeen A, Nazir A, Abbasi M, Rehman Z, Ullah Z. Elemental analysis of some medicinal plants used in traditional medicine by Atomic Absorption SpecTrophotometer (AAS). Journal of Medicinal Plants. 2010; 4(19):1987-90. DOI: 10.5897/JMPR10.081. https://doi. org/10.5897/JMPR10.081

57. Zhang JD, Cao YB, Xu Z, Sun HH, An MM, Yan L, Chen HS, Gao PH, Wang Y, Jia XM, Jiang YY. In vitro and in vivo antifungal activities of the eight steroid saponins from Tribulus terrestris $\mathrm{L}$ with potent activity against fluconazole-resistant fungal pathogens. Biological and Pharmaceutical Bulletin. 2005; 28(12):2211-5. DOI: JST. JSTAGE/bpb/28.2211[pii]. Available from: http://www. ncbi.nlm.nih.gov/ pubmed/16327151.

58. Zheleva-dimitrova D, Obreshkova D, Nedialkov P. Antioxidant activity of tribulus terrestris a natural product in infertility therapy. International Journal of Pharmacy and Pharmaceutical Sciences. 2012; 4(4):2-5. 